\title{
Analysis of IT Multisourcing Practice in a Telecommunication Company
}

\author{
Mehmet N. Aydin \\ Department of Management Information Systems, Faculty of Engineering and Natural Sciences, \\ Kadir Has University, Istanbul, Turkey
}

Correspondence should be addressed to: Mehmet N. Aydin; mehmet.aydin@khas.edu.tr

Received 8 September 2012; Accepted 11 July 2013; Published 28 November 2013

Academic Editor: Ra'ed (Moh'd Taisir) Masa'deh

Copyright (C) 2013 Mehmet N. Aydin. Distributed under Creative Commons CC-BY 3.0

\begin{abstract}
Organizations have used numerous sourcing strategies to realize an underlying value of IT from strategic and operational perspectives. However, a number of these sourcing strategies have failed to deliver on their expected outcomes. Multisourcing has been advanced as a form of sourcing which addresses the deficiencies of other failed strategies. This research attempts to examine the notion of benefits and risks for IT multisourcing so as to explore the underpinnings of IT multisourcing practice in the telecommunication industry. By employing a case study we found that the benefits identified are mainly associated with ability to lower IT costs, improvement of IT service levels and enabling access to specialist vendors for adaptive capability. The costs and risks of IT multisourcing addressed are related to vendor management, information security in general and effective service management across organizations in particular.
\end{abstract}

Keywords: Multisourcing, Outsourcing Strategies, Information Technology, Telecommunication.

\section{Introduction}

Information Technologies (IT) outsourcing has received considerable attention from both practitioners and academics over the past two decades. Organizations have used numerous sourcing strategies to realize an underlying value of information technologies (IT) from strategic and operational perspectives. The strategic perspective on IT sourcing addresses the need for aligning IT with strategic imperatives including competitive advantages, organizational agility to response to desired changes. From the operational perspective on IT sourcing, low cost and improved IT service support for business functions and processes is desired.

Attempts have been made to benefit from IT outsourcing by reducing operational costs involved in IT development and maintenance in such industries as government (Samsudin et al. 2013), healthcare (Roberts et al. 2013). With the help of publicized multi-billion outsourcing deals, most industries started to experience with IT outsourcing. However, scholars, including (Cohen \& Young 2006), mentioned a large number of IT outsourcing arrangements that failed to meet expectations. These failings can bring undesirable expense to organizations and 
have given rise to alternative sourcing strategies which have aimed to reduce IT costs, improve service levels and enable access to emerging technologies (Lacity \& Willcocks 1998). Multi-vendor sourcing, or multisourcing, is one such strategy.

Multisourcing can be defined as "the disciplined provisioning and blending of business and IT services from the optimal set of internal and external providers in the pursuit of business goals" (Cohen \& Young 2006 p.1). Under a multisourced IT strategy, a client organization can therefore outsource to vendors which have complementary capabilities and provide similar services (Levina \& Su 2008). Compare to other sourcing strategies, multisourcing has received only limited attention in especially the information systems literature. However, its origins may lie in the shortcomings of alternative IT outsourcing strategies. Past IS research has found that short-term outsourcing contracts achieved expected cost savings with a higher relative frequency than longterm contracts thereby suggesting that outsourcing contracts would get smaller over time. Selective sourcing was therefore a common IT sourcing strategy which was typified by short-term contracts for specific activities (Lacity et al. 1996).

Furthermore, outsourcing vendors were found to be experts only in certain fields (Edgell at al. 2008) and were less suited to the all-encompassing "mega-deals" with organizations. To address the inherent shortcomings of large IT outsourcing contracts, the notion of managing a small set of highly qualified and knowledgeable vendors has been advanced as a means of enabling flexibility, maintaining competitive prices and sustaining collaborative relationships with vendors (Poston et al. 2009). The flexibility in being able to select multiple vendors has been likened to "shoppers at a fruit stand" where organizations can "pick an apple here or an orange there" until they have selected a menu of outsourcing services (Lacity \& Hirschheim 1993). To this end, creating a portfolio of providers mitigates the risk associated with over-reliance on a single provider.
This research attempts to examine the notion of benefits and risks for IT multisourcing so as to explore the underpinnings of an IT multisourcing practice in the telecommunication industry. This paper is aimed to address the potential benefits, costs and risks of IT multisourcing in an empirical setting. A better understanding of these aspects will enable practitioners to ascertain whether IT multisourcing is a viable and sustainable sourcing strategy for their organizations. Thus, the key research question is as follows: What are the benefits, costs and risks of IT multisourcing? Throughout this paper, organizations that outsource IT functions will be referred to as "client organizations" and their outsourcing providers will be referred to as "vendors" or "providers." Consequently, this paper will consider multisourcing from the perspective of a client organization. Another delamination for the research design is that the case study is limited to IT infrastructure outsourcing, which seems to have distinct characteristics than other types of IT such as IT development and management.

The remaining sections of the paper are follows: Section 2 reviews academic IT outsourcing literature to discuss briefly the very notion of costs and risks of IT multisourcing. Section 3 explains the research methodology realized. Section 4 presents the case study and findings concerning the organization's transition into a multisourced IT environment. The findings will be compared with the reviewed studies as well. Finally, Section 5 discusses the limitations of this study and proposes a number of research questions for future research.

\section{Relevant Research}

Prior research in the wider domain of IT outsourcing has suggested that one of the greatest benefits of multisourcing can be conceptualized as flexibility by adjusting IT resources according to desired business outcomes. Tan and Sia (2006) maintain that a loss of flexibility through singlesourcing may limit a client organization's ability to change the extent, nature or 
scope of their outsourced services. Through a multisourced IT strategy, client organizations may have the flexibility to reshape outsourcing agreements with respect to varying cost saving targets, contract durations, service offerings. One may argue that a common maxim in IT is the need to do "more with less", which suggests that IT managers must continue to find ways of using IT to deliver business value whilst dealing with the challenge of lowering costs. Rotman (2008), based on the examination of a Fortune 100 manufacturer of industrial equipment which outsourced software development work to three providers, maintain that short-term contracts can keep vendors "on their toes" in that outsourcing arrangements can be extended based on how well each vendor has performed over the course of the relationship. Client organizations can also use the threat of market competition amongst existing vendors to gain the best price and service quality (Poston et al. 2009).

A multisourced IT strategy also enables client organizations to tailor the duration of individual contracts in accordance with their outsourcing objectives. Long-term contracts can often lead to vendors gaining substantial knowledge about clients' business and resources in general, their information systems in particular. Poston et al. (2009) point out that long-term relationships may evolve negatively over time to the extent that the client loses proprietary knowledge and give up the technological capabilities that other vendors are able to offer.

One of the most cited risks of outsourcing is vendor lock-in. This refers to situations when client organizations cannot terminate their IT outsourcing contracts without incurring a loss (Aubert et al. 2005). Lockin may occur when a given vendor accumulates proprietary knowledge about how a client organization's IT functions are performed. This is a natural risk in that a client organization can be held to ransom by their provider in the form of abovemarket costs. The principle of spreading this risk amongst multiple vendors through a multisourced strategy is already studied
(Aubert et al. 2005, Gottschalk \& SolliSaether 2006).

One of the implications of multisourcing is to reduce vendor-specific risks. On the vendor side, like all other organizations, outsourcing vendors must contend with business risks which can include negative cash flows, declining sales or a lack of innovation. Under any IT outsourcing arrangement, client organizations are limited to the technological capability of their chosen vendors which, in turn, could diminish over the life of a contract (Willcocks \& Lacity 1999). The flexibility of a multisourced strategy addresses this issue by recognising that different IT vendors are specialists in different areas. Client organizations can therefore draw on the capabilities of these specialist vendors by adding them to their outsourcing portfolios (McLellan et al. 1995).

A critical review of early IS outsourcing research suggested that several published reports of outsourcing presented only a promising picture of its benefits (Palvia 1995). Subsequent research has emphasized the need for exploring risk factors of an outsourced IT strategy (Barthélemy 2001). Not surprisingly, one of the common risk factors is related to poor vendor selection. IT practitioners will appreciate the practical relevance of these findings, particularly in knowing that evaluating and selecting vendors involves dealing with a level of ambiguity. This risk can be exacerbated in a multisourced environment where client organizations must take on the overhead associated with the search and evaluation of multiple vendors. Interestingly, the post-contract management of outsourcing relationships is a cost that several client organizations have also neglected to consider up front (Barthélemy, 2001). Accordingly, IS research has found that management costs rise as managers need to contract, coordinate, and collaborate with multiple providers (Levina \& Su 2008). In particular, the former brings trust, an understanding of the client's business (from a vendor perspective), a willingness to share risk and a reduction in client-vendor conflict (Lee 2001, Wüllenweber et al. 2008). 


\section{Research Methodology}

We conducted an interpretive case study to better understand the context and as well as dynamics of multisourcing in an empirical setting. Primary data was obtained by conducting two-rounds of four interviews with senior analists at a Telecommunication Company in a multisourced IT environment.

Our research needed a case where (a) a client organization was sourcing IT services from multiple providers, (b) the client organization had sufficient experience with multisourcing to the extent that its benefits, costs and risks were experienced or made evident, (c) the client organization could provide access to managers that could talk through their experiences with IT multisourcing, (d) those managers were willing and able to share their insights on the IT multisourcing practice examined.

Individuals were selected for interviews based on their knowledge of IT multisourcing and the degree to which they were involved in the decision to multisource. The interviews were conducted at the company, were face-toface, semi-structured and lasted for approximately an hour each. The interview language was English. Each interview was recorded and transcribed, sent back to the informants to provide additional feedback and for verification of the statements.

This research is explorative in nature and adopts a grounded theory approach. Data analysis was done with a particular coding method. Two academics and one practitioner were involved data analysis.

We used three groups of coding procedures, which are open, axial and selective coding (Baskerville \& Pries-Heje 1999). With open coding the incidents mentioned by the informants were labeled and consequently relations between the labeled statements or ideas were identified and categorized. Axial coding was needed to discover associations among the categories. Finally, selective coding helped to surface high-level categories which can logically link to the benefits, risks, and cost as guiding concepts in this research.

Several iterations were needed to reach a consensus for determining concepts by using labels for data categories. The goal was to find out what underpins the very notion of risk, benefit as the phenomenon under investigation. In this regard, the insights obtained from these interviews helped us to improve our understanding of the subject.

\section{IT Multisourcing at the Case Organization}

\section{Case Context and Outsourcing Background}

IT is a strategic business capability for telecommunication firms and provides services for supply chain, manufacturing, distribution and across a number of back office functions. For a long time, the case organization entered an IT infrastructure outsourcing contract with a global vendor. The underlying IT infrastructure is basis for all types of applications, their development, operations, and maintenance as well. This single-sourced arrangement covered the management of midrange servers, networks, desktop computers, laptop computers; helpdesk services and utility software. To this end, outsourcing was viewed as a means of reducing IT operating costs at the telecommunication (Telco) firm.

Whilst many IT functions were outsourced, the organization continued to perform a number of functions in-house. The teams dedicated Information Security and Compliance, Project Portfolio Management and Architectural Design, Customer Applications, Billing and Pricing and System and Security are predominantly centralized (See Table 1 below).

The organization changed the outsourcing contract in order to lower costs, and they contracted with multi suppliers for sourcing their IT infrastructure. The informants acknowledged the reason for changing outsourcing strategy with different viewpoints. One of them stated, 
"We had some problems in some areas with single-sourcing, including cost, and we had to change our strategy to multisourcing."

Changing to a multisourcing strategy required the organization to search for many distinct providers. An analyst interviewed stated, "It is difficult to find a vendor that can provide every service with a high level of quality. If you look for required particular capabilities and competencies in the market and if you target those vendors, you get a better outcome because there are certainly different providers which have their own sweet spots."

With a multisourcing environment, the organization needed to integrate a multiple of services provided by various vendors. Such integration needed to be done carefully as it requires technical and organizational interoperability.

Another analyst of the organization stated that "There are a lot of companies out there that do a lot of selective sourcing i.e. they have some functions in-house, they use Vendor $A$ to do some things and $B$ to do other things and $C$ to do different things. I think there is a big difference between "multisourcing" and "true multisourcing" is being that it is actually integrating $A, B$ and $C$ vendors to work together within one operating model."

\section{Table 1: Overview of IT Infrastructure Services Outsourced}

\begin{tabular}{|l|l|}
\hline Vendors & IT services \\
\hline A1, A2, A3 & IT helpdesk, desktop and laptop support \\
\hline B1, B2 & data center management, storage area network management \\
\hline $\begin{array}{l}\text { C1, C2, } \\
\text { C3,C4, C5 }\end{array}$ & Operations \\
\hline $\begin{array}{l}\text { D1, D2, D3, } \\
\text { D4 }\end{array}$ & Application Support and Testing \\
\hline E1, E2 & Enterprise Software Applications \\
\hline
\end{tabular}

The organization had to develop an effective services management layer with multisourcing and they can do this with creating processes which are governed by each vendor. For this layer, the case organization organized workshops with their vendors for setting a basis on which successful communication and streamlined processes across vendors can be achieved.

An analyst stated that, "There are always some generic management tools in the telco firms that can be used for a Change Management or an Incident Management. But even two vendors can support such tools, often times one can face issues with integration of these tools as they are modified to organizations' needs. This is essential to realize collaboration among vendors effectively."
In order to facilitate this collaboration between vendors, the client organization gave the vendors a certain degree of freedom to establish how they would integrate and collaborate within the client multisource environment.

One of the analysts commented that "the other thing we are getting in place is what we call "operating level agreements". They are not contractual agreements but are instead expectations that the parties have about each other and which contribute to the organization's outcomes".

Another analyst support the idea that "We want you guys to work together and you guys document how you are going to do that and what your expectations are." 


\section{Benefits of IT Multisourcing}

The move to a multisourced environment was motivated by a number of factors. One of the most cited terms was flexibility for sustaining capabilities. In contrast to single-sourced arrangement, this strategy was valued as possibility of highly flexible arrangements.

An analyst stated, "I think we went to multisourcing because it provides a more flexible distributed capability gained from more than one vendor to work on projects. In this way, every piece of work can be assigned to each vendor. This is not possible with single-sourced outsourcing."

One of the common perceptions on multisourcing is that the Telco firm wanted to get vendors specialized for their each application, so multisourcing was the best way to do it.

More specifically an analyst stated, "Given new IT services requested for the changing business environment we needed new applications to manage our systems. Internally, we could expect a person specialized about all applications. So, we can make use of external resources as separate specialists who are experts on their own topic. This is an advantage to manage our applications and in turn meet the business needs."

The number of projects and nature of work were changing as the business offers campaigns related services. This means that adjustment of workload should be possible with short-term multisourcing. This is indeed mentioned by informants explicitly. For instance, an analyst stated "We are responsible for many projects at the same time. When we were working with a single vendor, they cannot get all projects done at the same time. With multisourcing, while a vendor is engaged in a project, the other vendor can work on other projects concurrently."

When the Telco firm worked with single sourcing, they were locked-in to that organization, which is also cited as a common problem. It is commented that this locked-in was unsolved issue and the client organization had to adjust its plan to the vendor rather than the other way around. An analyst confirmed, "We cannot do our planning work whenever we want because vendors are working with many companies. So, they have some priorities. However, if we work with different vendors in our company, we will have chance to have a B-plan, that is, an alternative plan in case one vendor fails to deliver the work on time."

Another issue was related to headcount. It is stated, "When we contracted just with one vendor to operate our applications, things were going very slowly. Ironically, we had to increase in-house headcount. Simply, we considered multisourcing as yet another strategy to decrease in-house headcount."

Multisourcing can reduce the cost due to bargaining power. As stated, "While working with multisourcing vendor, our bargaining power can increase. Working with more than one vendor may create price competition between firms"

\section{Costs and Risks of IT Multisourcing}

Having experienced with unprecedented risks with single sourcing, senior analysts at the Telco firm wanted to reduce IT risks. The findings from our interviews suggested that there is an agreed perception on risk management in that the client organization appeared to succeed in lowering its IT risk through multisourcing. Risks were distributed over each provider.

An analyst confirmed that perception in his statement as follows: "We transferred risk of the projects to each provider. When you contract with multiple providers, you can assign each work to one of providers and if they fail to provide the expected service, we refer to the contract and take actions accordingly."

Going with multisourcing inherently brings up other costs and risks. The degree and realization of control was addressed as one of major challenges. An analyst stated that "Before multisourcing, vendors' control was easy for us, because many companies have approximately 2 and 4 analysts to manage a 
vendor. Now, we have more analysts, but we have also too many vendors. This simply required a different type of control as the number of interactions within our organization and across vendors are increased."

In this regard, to coordinate and control vendors are very hard for the analysts. An analyst stated, "Sometimes, we can work for a project with more than one vendor, and then we need several meetings for the project plan. But, coordination of vendors is very hard because they are experienced with working together, they used to work their own projects as a single vendor."

Analysts commented that quality of the service provided did not meet expectations especially in those projects where vendors' services are tightly coupled. An analyst stated, "In some situations working with multisourcing can raise the question of expected quality. We have to control and test the results of the each project step, carefully. In case vendors cannot integrate their services with other vendors, we have to take some additional actions to ensure that services are interoperable."

Another risk issue in multisourcing mentioned is related to vendor selection.

An analyst stated, "We want to find vendors which are expert on their side. Therefore, vendor selection is an ongoing operation for us. We search for each vendor backgrounds and sponsors from a multisourcing perspective, which requires a different mindset compare to a single sourcing."

It is also commented that information disclosure as perceived as information security is more risky at multisourcing then single sourcing. An analyst maintain that "While we are working with single-sourcing, we share our some confidential information with just one vendor, but now, we share them with more than one vendor and those vendors may work with our rival firms and they can share our sensitive information or so, we need to be more careful."

Based on the data analysis (labeling for concepts) as explained in Section 3, we summarized our findings with the multisourcing literature in general and the Fonterra's case in particular (Barboza et al. 2011) (see Table 1). The reason for comparing our result with Fonterra's case is its similarity with ours in terms of research scope, data analysis, and research inquiry. Grey cells in the last column indicate those findings which are not found in the literature explicitly. Some of these differences may result from such factors as the client characteristics, industry difference. For instance, "ability to do more planned work" might be related to client's and/or vendor's collaboration experiences. 
Table 2: Summary of the findings from the Case and Comparative View

\begin{tabular}{|c|c|c|c|}
\hline $\begin{array}{l}\text { The Case } \\
\text { Organization }\end{array}$ & $\begin{array}{l}\text { Fonterra case (Barboza } \\
\text { et al. 2011) }\end{array}$ & Literature in general & Overall comparison \\
\hline Transfer risk & $\begin{array}{l}\text { Not explicitly considered } \\
\text { in Fonterra }\end{array}$ & $\begin{array}{l}\text { Transfer risk (Aubert et al. 2005, } \\
\text { Gottschalk \& Solli-Saether 2006), Lee } \\
\text { 2001, Wüllenweber et al. 2008) }\end{array}$ & Corroborates literature \\
\hline $\begin{array}{l}\text { Distributed } \\
\text { capability }\end{array}$ & $\begin{array}{l}\text { Not explicitly considered } \\
\text { in Fonterra }\end{array}$ & Distributed capability (Tan \& Sia 2006) & Corroborates literature \\
\hline Specialist vendor & Specialist vendor & $\begin{array}{l}\text { Specialist vendor (Cross 1995, McLellan } \\
\text { e al. 1995, Willcocks \& Lacity 1999) }\end{array}$ & $\begin{array}{l}\text { Corroborates } \\
\text { literature and Fonterra }\end{array}$ \\
\hline Parallel projects & $\begin{array}{l}\text { Not explicitly considered } \\
\text { in Fonterra }\end{array}$ & Parallel projects & $\begin{array}{l}\text { Corroborates } \\
\text { literature }\end{array}$ \\
\hline $\begin{array}{l}\text { Ability to do more } \\
\text { planned working }\end{array}$ & $\begin{array}{l}\text { Not explicitly considered } \\
\text { in Fonterra }\end{array}$ & $\begin{array}{l}\text { Not explicitly considered in existing } \\
\text { academic literature }\end{array}$ & \\
\hline Reduce headcount & $\begin{array}{l}\text { Not explicitly considered } \\
\text { in Fonterra }\end{array}$ & $\begin{array}{l}\text { Not explicitly considered in existing } \\
\text { academic literature }\end{array}$ & \\
\hline $\begin{array}{l}\text { Reduce } \\
\text { dependency }\end{array}$ & May reduce dependency & May reduce dependency & $\begin{array}{l}\text { Corroborates } \\
\text { literature }\end{array}$ \\
\hline $\begin{array}{l}\text { Management } \\
\text { problem }\end{array}$ & $\begin{array}{l}\text { Not explicitly considered } \\
\text { in Fonterra }\end{array}$ & $\begin{array}{l}\text { Management problem (Barthélemy } \\
\text { 2001) }\end{array}$ & $\begin{array}{l}\text { Corroborates } \\
\text { literature }\end{array}$ \\
\hline $\begin{array}{l}\text { Coordination } \\
\text { problem }\end{array}$ & $\begin{array}{l}\text { Not explicitly considered } \\
\text { in Fonterra }\end{array}$ & $\begin{array}{l}\text { Coordination problem (Levina \& Su } \\
2008 \text { ) }\end{array}$ & $\begin{array}{l}\text { Corroborates } \\
\text { literature }\end{array}$ \\
\hline Quality issue & $\begin{array}{l}\text { Not explicitly considered } \\
\text { in Fonterra }\end{array}$ & $\begin{array}{l}\text { Not explicitly considered in existing } \\
\text { academic literature }\end{array}$ & \\
\hline $\begin{array}{l}\text { Vendor selection } \\
\text { problem }\end{array}$ & $\begin{array}{l}\text { Not explicitly considered } \\
\text { in Fonterra }\end{array}$ & Vendor selection problem & $\begin{array}{l}\text { Corroborates } \\
\text { literature }\end{array}$ \\
\hline Bargaining power & Bargaining power & Bargaining power (Poston et al. 2009) & $\begin{array}{l}\text { Corroborates } \\
\text { literature and Fonterra }\end{array}$ \\
\hline $\begin{array}{l}\text { Information } \\
\text { security risk and } \\
\text { control }\end{array}$ & $\begin{array}{l}\text { Not explicitly considered } \\
\text { in Fonterra }\end{array}$ & $\begin{array}{l}\text { Not explicitly considered in existing } \\
\text { academic literature }\end{array}$ & \\
\hline $\begin{array}{l}\text { Inconclusive from } \\
\text { the interviews }\end{array}$ & $\begin{array}{l}\text { Reduce infrastructure } \\
\text { cost }\end{array}$ & $\begin{array}{l}\text { Not explicitly considered in existing } \\
\text { academic literature }\end{array}$ & \begin{tabular}{|l} 
Corroborates \\
Fonterra
\end{tabular} \\
\hline Cost Saving & Cost Saving & Cost Saving (Rottman 2008) & $\begin{array}{l}\text { Corroborates } \\
\text { literature and Fonterra }\end{array}$ \\
\hline $\begin{array}{l}\text { Temporary } \\
\text { increase in-house } \\
\text { headcount }\end{array}$ & $\begin{array}{l}\text { Temporary increase in- } \\
\text { house headcount }\end{array}$ & $\begin{array}{l}\text { Not explicitly considered in existing } \\
\text { academic literature }\end{array}$ & $\begin{array}{l}\text { Corroborates } \\
\text { Fonterra } \\
\end{array}$ \\
\hline $\begin{array}{l}\text { Inconclusive from } \\
\text { the interviews }\end{array}$ & $\begin{array}{l}\text { Not explicitly considered } \\
\text { in Fonterra }\end{array}$ & High quality (Rottman 2008) & $\begin{array}{l}\text { Corroborates } \\
\text { literature }\end{array}$ \\
\hline
\end{tabular}

This seems to a side benefit with working with multi-vendors and deserves a further investigation. "Reduce headcount" seems to a surprising finding in that on the one hand it contributes to cost reduction, but the analyst commented the other way around in that the cost may arise due to the need for temporary in-house headcount especially for better control and coordination. Other labels, "Quality issue" and "Information Security Risk", are worth noticing to explore further how they are perceived in other contexts.

\section{Conclusions}

The objective of this paper was to provide a preliminary understanding of the benefits, costs and risks of IT multisourcing. Our analysis and discussion of the 
Telecommunication (Telco) case enabled us to obtain this understanding and contributes to the limited body of IS research on multisourcing. Our specific contribution to IS research stems from how the Telco case corroborates and contradicts the literature as presented in Table 2. In the context of multisourcing, a number of issues including information security risks, planned way of working, temporary increase in in-house headcount for better control and coordination were found to be perceived and realized differently than in single sourcing. The case study thus contributes to practice as IT analysts in Telco's can learn from the successful transition to multisourcing and be aware of emerging risk factors.

There are, of course, various limitations of this study. Many IT outsourcing studies have examined outsourcing relationships over a longer period of time to examine how these relationships have evolved. Our study is limited by the short time frame of our case study. Another limitation is that this case is limited a specific industry and organization characteristics. Nevertheless, the limitations of this study suggest avenues for future research concerning the effect of industry, organization, and services characteristics on IT multisourcing.

This research also contributes to the observation of multisourcing practice that IT sourcing arrangements tend to evolve to include multisourcing as a viable sourcing strategy. Whilst the different types of costs and risks of IT multisourcing must be taken into account, the value of this strategy seems to lie in its potential to lower costs, flexibility capability, improve IT service levels and enable access to specialist vendors and emerging technologies. With this in mind, multisourcing is likely to become one of the promising IT sourcing strategies.

\section{Acknowledgement}

I would like to gratefully thank Erdem Bingöl for his contribution to the early version of this work. His support during the data collection and analysis is greatly appreciated.

\section{References}

Aubert, B. A., Patry, M. \& Rivard, S. (2005). "A Framework for Information Technology Outsourcing Risk Management," The DATA BASE for Advances in Information Systems, 35(4), 9-28.

Barboza, M., Myers, M. \& Gardner, L. (2011). "Information Technology Multisourcing at Fonterra: A Case Study of the World's Largest Exporter of Diary Ingredients," ECIS 2011 Proceedings. Paper 44.

Barthélemy, J. (2001). "The Hidden Costs of IT Outsourcing," MIT Sloan Management Review (Spring), 60-69.

Baskerville, R. \& Pries-Heje, J. (1999). "Grounded Action Research: A Method for Understanding IT in Practice," Accounting Management and Information Technologies, 9(1), 1-23.

Cohen, L. \& Young, A. (2006). Multisourcing: Moving Beyond Outsourcing to Growth and Agility, Harvard Business School Press, Boston, MA.

Cross, J. (1995). "IT Outsourcing: British Petroleum's Competitive Approach," Harvard Business Review, Harvard Business School Publishing, 94-102.

Edgell, J., Meister, G. E. \& Stamp, N. (2008). "Global Sourcing Trends in 2008," Strategic Outsourcing: An International Journal, 1(2), 173-180.

Gottschalk, P. \& Solli-Saether, H. (2006). "Managing Successful It Outsourcing Relationships," Hershey, PA: IRM Press.

Lacity, M. C. \& Hirschheim, R. (1993). 'The Information Systems Outsourcing Bandwagon,' MIT Sloan Management Review (Fall), 73-86. 
Lacity, M. C. \& Willcocks, L. P. (1998). “An Empirical Investigation of Information Technology Sourcing Practices: Lessons from Experience," MIS Quarterly, 67-93.

Lacity, M. C., Willcocks, L. P. \& Feeny, D. F. (1996). "The Value of Selective It Sourcing," MIT Sloan Management Review (Spring), 13-25.

Lee, J.- N. (2001). "The Impact of Knowledge Sharing, Organizational Capability and Partnership Quality on Is Outsourcing Success," Information \& Management, (38), 323-335.

Levina, N. \& Su, N. (2008). "Global Multisourcing Strategy: The Emergence of a Supplier Portfolio in Services Offshoring," Decision Sciences, 39(3), 541-570.

McLellan, K., Marcolin, B. L. \& Beamish, P. W. (1995). "Financial and Strategic Motivations Behind IS Outsourcing," Journal of Information Technology, 10, 299321.

Palvia, P. C. (1995). "A Dialectic View of Information Systems Outsourcing: Pros and Cons," Information \& Management, 29, 265275.

Poston, R. S., Kettinger, W. J. \& Simon, J. C. (2009). "Managing the Vendor Set: Achieving Best Pricing and Quality Service in It Outsourcing," MIS Quarterly Executive, 8(2), 45-58.

Roberts, J. G., Henderson, J. G., Olive, L. A. \& Obaka, D. (2013). "A Review of Outsourcing of Services in Health Care Organizations," Journal of Outsourcing \& Organizational Information Management, Vol. 2013 (2013), Article ID 985197.

Rottman, J. W. (2008). "Successful Knowledge Transfer within Offshore Supplier Networks: A Case Study Exploring Social Capital in Strategic Alliances," Journal of Information Technology, 23, 3143.
Samsudin, N. M., Hashim, R. \& Fuzi, S. F. S. M. (2013). "Electronic Government Outsourcing Issues in Malaysia," Journal of Outsourcing \& Organizational Information Management, Vol.2013 (2013), Article ID 619305.

Tan, C. \& Sia, S. K. (2006). "Managing Flexibility in Outsourcing," Journal of the Association for Information Systems, 7(4), 179-206.

Willcocks, L. P. \& Lacity, M. C. (1999). "IT Outsourcing in Insurance Services: Risk, Creative Contracting and Business Advantage," Information Systems Journal, 9, 163-180.

Wüllenweber, K., Jahner, S. \& Krcmar, H. (2008). "Relational Risk Mitigation: The Relationship Approach to Mitigating Risks in Business Process Outsourcing," 41st Hawaii International Conference on System Sciences, Waikoloa, Big Island, Hawaii. 